\title{
INTERROGANTES DE LA METALURGIA PREHISPÁNICA ANDINA. NUEVAS PROPUESTAS DESDE LOS HORNOS DE QUILLAY (CATAMARCA, ARGENTINA)
}

\author{
QUESTIONS OF ANDEAN PREHISPANIC METALLURGY. NEW PROPOSALS \\ FROM THE QUILLAY FURNANCES (CATAMARCA, ARGENTINA)
}

\author{
Josefina Spina ${ }^{1}$, Marco Giovannetti ${ }^{1,2}$ y Edgardo Ferraris ${ }^{3}$
}

\begin{abstract}
El sitio arqueológico Quillay (Catamarca, Argentina) es considerado como un centro de extracción de metal a gran escala, debido a la presencia de numerosos hornos con funciones metalúrgicas. Este trabajo tiene como objetivo presentar los resultados de excavaciones de las estructuras de combustión identificadas en el sitio. Los nuevos estudios permitieron conocer la morfología completa de un conjunto importante de hornos, los cuales exponen características que se alejan de aquellas propuestas conocidas para las wayras andinas. Desarrollamos aquí una minuciosa descripción de los hornos, presentamos los resultados preliminares de análisis técnicos efectuados sobre escorias y proponemos algunas interpretaciones que permiten pensar en su dinámica de funcionamiento.

Palabras claves: Quillay, hornos de fundición, período Tardío/Inka.
\end{abstract}

The archaeological site Quillay (Catamarca, Argentina) is considered as a large scale ore processing/smelting center given the presence of numerous furnaces with metallurgical functions. This paper presents the results of excavations of the combustion structures identified at the site. The new studies allowed knowing the complete morphology of an important set of furnaces, which exhibit features that differ from those accounted for in Andean wayras. In this paper, we give a detailed description of the furnaces, present the preliminary results of the technical analysis of slags, and propose some interpretations which suggest the operation of these structures.

Key words: Quillay, smelting furnace, Late/Inka period.

El valle de Hualfín en Catamarca, Argentina, se erige como un paisaje que ha jugado un rol principal en la historia prehispánica del Noroeste argentino (NOA). Se puede recorrer en su propia línea del tiempo desde las primeras aldeas agroalfareras, pasando por el surgimiento de señoríos complejos como la entidad cultural Aguada y llegar hasta las épocas de conflictos internos del período Tardío (González y Cowgill 1975). Más tarde, los Inkas se asentarían sobre un contexto social dominado por entidades culturales que los arqueólogos denominamos Belén, cuyos sitios de vivienda, defensivos y campos agrícolas se diseminaban por todo el valle (Balesta et al. 2011). Quillay es un caso extraño, no solo dentro de este panorama sino posiblemente en todo el NOA. Se trata de un asentamiento de unos pocos recintos de piedra que no aportarían mucho si no fuera por la impactante acumulación de hornos metalúrgicos en sus alrededores. A la fecha se han registrado 33 unidades de estas estructuras de combustión que se disponen unas veces en conjuntos y otras veces como hornos individuales. Los recintos del sector, que llamaremos por el momento "habitacional", se componen de 12 unidades -ocho recintos y cuatro anexos- desplegados en sentido N-S. Los hornos se ubican en un radio de hasta dos $\mathrm{km}$ a la redonda de este sector (Figura 1).

En la actualidad, la región está prácticamente deshabitada a excepción de una única familia de campesinos criadores de ganado caprino. Su vivienda se ubica a escasos $100 \mathrm{~m}$ del sector habitacional del sitio, siendo muchas de las rocas de la casa de esta familia procedentes de los recintos arqueológicos.

El entorno natural se describe como un barrial (acumulaciones sedimentarias eólicas) de clima seco con abundantes plantas xerófilas y árboles como el algarrobo (Prosopis sp.) y el chañar (Geoffroea

\footnotetext{
1 División Arqueología, Museo de Ciencias Naturales de La Plata, Facultad de Ciencias Naturales y Museo, Universidad Nacional de La Plata, Argentina. josefinaspina@gmail.com

2 Consejo Nacional de Investigaciones Científicas y Técnicas CONICET, Argentina. marcogiovannetti@gmail.com

3 Facultad de Ciencias Naturales y Museo, Universidad Nacional de La Plata, Argentina. edgardo_ferraris@ @otmail.com
} 


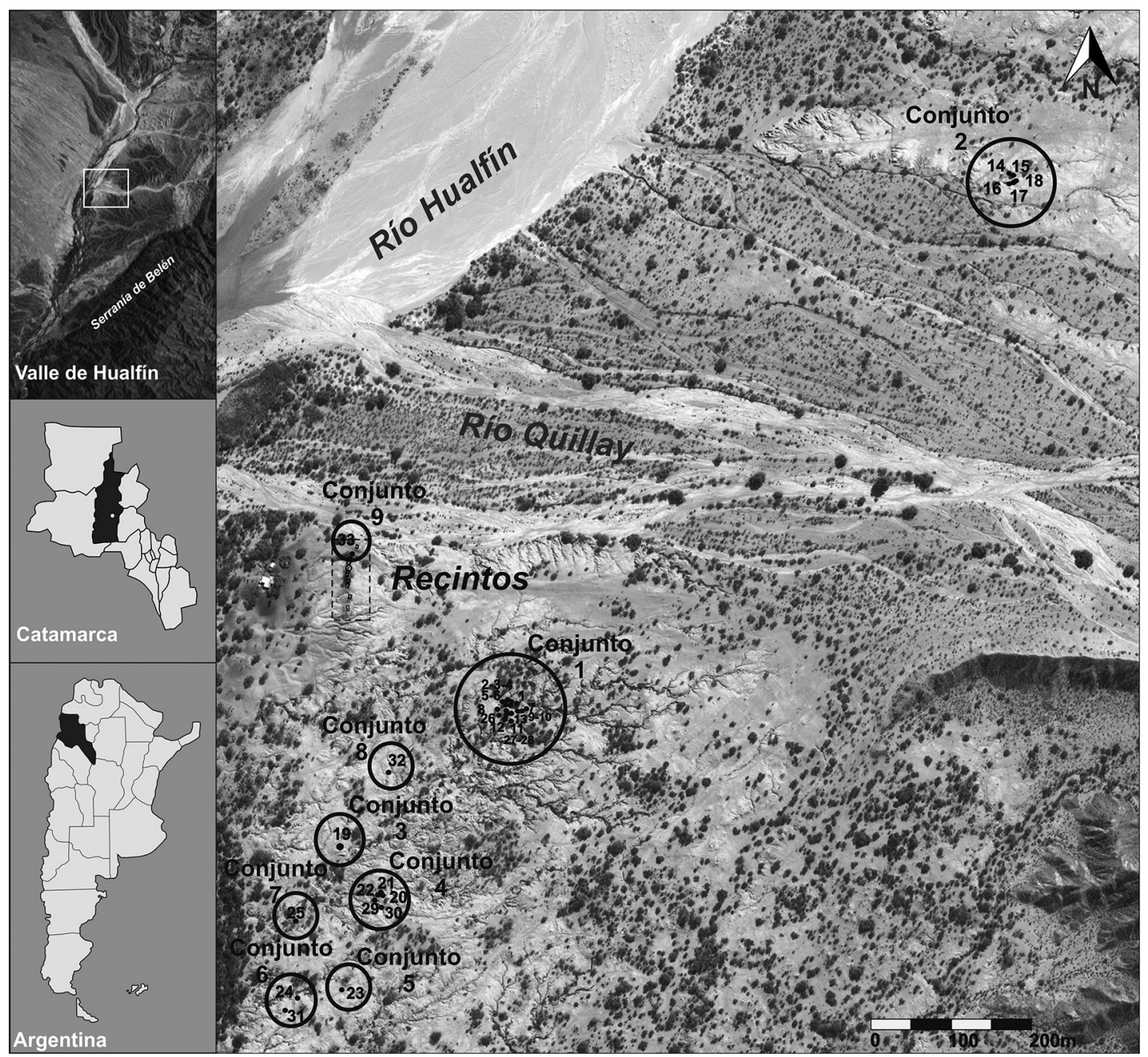

Figura 1. Mapa de Quillay con la ubicación de los recintos y los conjuntos de hornos metalúrgicos. Montado sobre imagen del servidor Bing 2015.

Map of Quillay showing the location of the rooms and the sets of metallurgical furnaces. Mounted over Bing 2015 server image.

decorticans). También arbustos como la jarilla (Larrea sp.) y la retama (Senna crassiramea) y el que suponemos le da nombre al río que a su vez da nombre a la zona, el quillay (Bredemeyera colletioides). El sitio arqueológico se dispone en la zona de confluencia de dos cauces de agua, uno actualmente seco, el Quillay, y otro de agua permanente, el río Hualfín que es el colector principal del valle.

Las investigaciones realizadas en el sitio han presentado una discontinuidad temporal que resultaron en dos publicaciones específicas (González 1959; Raffino et al. 1996) y algunas menciones en trabajos que abordan la problemática Inka en la región (González 1980; Raffino 2009;
Raffino et al. 1983-1985; Raffino et al. 2013). El primero en publicar los resultados de excavaciones y prospecciones fue González (1959), quien mostró los resultados de los materiales hallados en los recintos. Allí obtuvo cerámica Inka provincial en asociación a tiestos de estilos locales tardíos, conjunto que hemos podido reestudiar y confirmar su clasificación tipológica.

Raffino et al. (1996) retomaron los estudios del sitio dando cuenta de la existencia de 14 hornos. A su vez recolectaron cerámica de superficie y muestras de carbón y escoria para diferentes análisis. Dos fechados radiocarbónicos arrojaron los siguientes resultados: AC-0553: 390 \pm 100 a.p. y AC-0552: 
$460 \pm 100$ a.p., estos datos posicionan al sitio en el período de ocupación Inka para el valle (Raffino et al. 1996:64). Junto con la publicación de los fechados los autores presentaron un primer croquis de los hornos, elaborado a base de la parte visible de estos, por lo que, como veremos más adelante, las excavaciones realizadas por nosotros arrojan hoy un esquema diferente de estas estructuras.

Un trabajo recientemente publicado por nosotros tuvo como objetivo exponer el descubrimiento de una cantidad mayor de hornos $(n=32)$ y el relevamiento de su estado de conservación denunciando que muchas estructuras, si no han desaparecido ya, corren un serio riesgo en un futuro cercano (Spina y Giovannetti 2014). La Tabla 1 muestra las zonas en las que dividimos los conjuntos de hornos de acuerdo a cómo se encuentran agrupados y una evaluación del estado de conservación de cada uno. Como se puede observar, los hornos están distribuidos en un amplio espacio y a distancias relativamente largas de hasta un kilómetro respecto de los recintos. A excepción de un horno aislado, descubierto recientemente en el sector de recintos, el conjunto de hornos más cercano (conjunto ${ }^{\circ} 1$ ) se

Tabla 1. Distribución y características de los hornos de Quillay. Distribution and characteristics of furnaces at Quillay.

\begin{tabular}{|c|c|c|c|c|}
\hline $\mathrm{N}^{\mathrm{o}}$ de conjunto & $\begin{array}{l}\text { Distancia desde } \\
\text { el recinto } 1(\mathrm{~m})\end{array}$ & $\mathrm{N}^{\mathrm{o}}$ de horno & Asociación & $\begin{array}{c}\text { Grado de } \\
\text { conservación }\end{array}$ \\
\hline \multirow{16}{*}{1} & \multirow{16}{*}{$285 \mathrm{SE}$} & 1 & $\mathrm{i}$ & 2 \\
\hline & & 2 & a & 3 \\
\hline & & 3 & $\mathrm{a}$ & 3 \\
\hline & & 4 & $\mathrm{a}$ & 3 \\
\hline & & 5 & $\mathrm{i}$ & 3 \\
\hline & & 6 & $\mathrm{i}$ & 3 \\
\hline & & 7 & $\mathrm{i}$ & 2 \\
\hline & & 8 & $\mathrm{i}$ & 3 \\
\hline & & 9 & $\mathrm{i}$ & 2 \\
\hline & & 10 & $\mathrm{i}$ & 2 \\
\hline & & 11 & $\mathrm{i}$ & 2 \\
\hline & & 12 & $\mathrm{i}$ & 3 \\
\hline & & 13 & $\mathrm{i}$ & 2 \\
\hline & & 26 & $\mathrm{i}$ & 2 \\
\hline & & 27 & $\mathrm{a} ?$ & 3 \\
\hline & & 28 & $\mathrm{i}$ & 2 \\
\hline \multirow{5}{*}{2} & \multirow{5}{*}{$934 \mathrm{NE}$} & 14 & $\mathrm{i}$ & 1 \\
\hline & & 15 & $\mathrm{i}$ & 1 \\
\hline & & 16 & $\mathrm{i}$ & 1 \\
\hline & & 17 & $\mathrm{i}$ & 1 \\
\hline & & 18 & $\mathrm{i}$ & 1 \\
\hline 3 & $395 \mathrm{~S}$ & 19 & $\mathrm{i}$ & 3 \\
\hline \multirow{5}{*}{4} & \multirow{5}{*}{$474 \mathrm{SE}$} & 20 & $\mathrm{i}$ & 1 \\
\hline & & 21 & $\mathrm{i}$ & 1 \\
\hline & & 22 & $\mathrm{i}$ & 1 \\
\hline & & 29 & $\mathrm{i}$ & 2 \\
\hline & & 30 & $\mathrm{i}$ & 3 \\
\hline 5 & $596 \mathrm{~S}$ & 23 & $\mathrm{i}$ & 3 \\
\hline \multirow{2}{*}{6} & \multirow{2}{*}{$614 \mathrm{~S}$} & 24 & $\mathrm{i}$ & 2 \\
\hline & & 31 & i & 2 \\
\hline 7 & $509 \mathrm{~S}$ & 25 & $\mathrm{i}$ & 2 \\
\hline 8 & $306 \mathrm{SE}$ & 32 & $\mathrm{i}$ & 2 \\
\hline 9 & $20 \mathrm{~S}$ & 33 & $\mathrm{i}$ & 1 \\
\hline
\end{tabular}

1= Exhiben un buen estado de conservación al preservar su estructura completa. $2=$ Estado regular, conservan su base y/o segmentos de pared. $3=$ Destruido. 
ubica a casi $300 \mathrm{~m}$ de distancia, pero a pesar de esta dispersión, todos comparten patrones arquitectónicos similares que los engloban dentro de un mismo tipo. En superficie se visualiza siempre una estructura tubular que, en el extremo superior, se curva hacia el interior a la manera de un cono, finalizando en una abertura horizontal que pudo haber tenido aproximadamente 50 o $60 \mathrm{~cm}$ de diámetro.

Como se observa en la Figura 1, los conjuntos de hornos de Quillay se agruparon heterogéneamente de acuerdo con su cantidad. El más numeroso presenta 16 ejemplares (conjunto $n^{\circ} 1$ ), algunos de las cuales se disponen en serie de tres con paredes que se tocan entre sí. Este conjunto está surcado por profundas cárcavas que han producido la destrucción de varios hornos. Otros conjuntos contienen un solo ejemplar o se presentan en número de cinco (conjuntos $\mathrm{n}^{\circ} 2$ $\left.\mathrm{y} \mathrm{n}^{\circ} 4\right)$. A diferencia del conjunto $\mathrm{n}^{\circ} 1$, hay casos en que el espacio circundante es llano, esto nos hace suponer que no se emplazarían al momento de su construcción sobre cárcavas profundas como las que hoy se observan.

Por otra parte, consideramos importante remarcar el contexto social regional en el cual las actividades productivas en Quillay fueron desarrolladas. En este sentido, para el valle de Hualfín se han propuesto dinámicas variables con relación al grado de intervención inkaica en las poblaciones locales. Por un lado, un panorama de fragmentación política entre diferentes grupos Belén que se habrían aliado o confrontado con los Inkas, resultaría en un aumento de la conflictividad (Balesta et al. 2011). Por el otro, una situación de control estatal más homogéneo con la implantación de sitios inkaicos de relevancia como Hualfín Inka no expondría situaciones de tensiones permanentes (Lynch 2013).

Frente a estas propuestas, Quillay se inserta como un sitio con una materialidad no muy diversa desde los elementos como la cerámica, con la presencia mayoritaria del estilo Belén tanto en contextos de habitación como en los hornos. Pero la disposición espacial de los recintos en alineamiento N-S, sumado al menos a una decena de fragmentos cerámicos de estilo Inka provincial, responde a una lógica estatal.

\section{El Problema de la Clasificación de los Hornos de Quillay}

En las publicaciones acerca de metalurgia andina está ampliamente difundida la categoría wayra para hacer referencia a una clase particular de hornos de fundición de épocas prehispánicas y coloniales, cuyas primeras menciones aparecen en los escritos de los siglos XVI y XVII (Barba 1817 [1640]; Capoche 1959 [1585]; Cieza de León 1922 [1553]; entre otros). Sin embargo, la exploración de las crónicas nos sitúa frente a un panorama de descripciones múltiples de estas estructuras de fundición que, siendo englobadas bajo el mismo término de wayra, exponen gran variedad de formas, materias primas y grado de transportabilidad (Bargalló 1967; Boman 1991 [1908]; De Nigris y Riart 2011; Petersen 1970; Téreygeol y Cruz 2014) ${ }^{1}$. Las variantes en las descripciones evidencian una gran complejidad en la relación tipológica que se establece en las crónicas que invita a pensar en el alcance de la categoría.

A pesar de ello, algunos investigadores ya han sugerido que de las fuentes coloniales se pueden extraer ciertos atributos diagnósticos o distintivos del tipo wayra, considerando estas características como fundamentales para la identificación arqueológica de hornos de este tipo. Estos atributos son: (1) la presencia de orificios que perforan la pared de los hornos, y (2) su localización en regiones con fuertes vientos, relacionado a zonas topográficamente altas (Téreygeol y Cruz 2014; Van Buren y Mills 2005). Ambos rasgos responderían a un conjunto de requerimientos técnicos, dado que la presencia de vientos fuertes en zonas altas y el ingreso constante de aire por los orificios, permitiría la circulación de los gases necesarios para las reacciones químicas en su interior y favorecería la combustión. De esta manera las wayras funcionarían como hornos de ventilación natural (González 2004a; Van Buren y Mills 2005; entre otros).

Los hornos de Quillay fueron históricamente referenciados como wayras andinas (Raffino et al. 1996; Raffino et al. 2013). Sin embargo, teniendo en cuenta la sistematización previamente desarrollada, esta clasificación no queda exenta de dudas. González (2004a), por ejemplo, revisa la propuesta realizada por Raffino et al. (1996), texto en el cual los autores plantean la probable existencia de perforaciones laterales a la manera de las wayras andinas, localizadas, supuestamente, en el tercio superior de la estructura. Para González "la ubicación de los orificios... no habría sido la más conveniente para optimizar el funcionamiento del horno" (González 2004a:116). Incluso, en nuestro trabajo anterior (Spina y Giovannetti 2014) exponíamos que no contábamos aún con elementos suficientes para 
asegurar siquiera la existencia de perforaciones. Hoy, luego de nuestros recientes estudios podemos afirmar que no existieron y que lo que observamos en su momento fueron solo orificios accidentales productos del deterioro natural. Los hornos de Quillay son estructuras fijas de tierra cocida, de dimensiones mayores a aquellas propuestas por los cronistas, que no cuentan con los orificios de ventilación, por lo cual, refutamos la idea de asociar los hornos a la categoría específica de wayra.

\section{“Radiografía” de los Hornos de Quillay}

Los hornos que presentamos aquí fueron excavados en dos campañas sucesivas realizadas entre 2012 y $2013^{2}$. Se excavaron tres hornos: los H14 y H17 del conjunto de hornos nº 2 y el H7 del conjunto $\mathrm{n}^{\circ} 1$. Fueron seleccionados por su buen estado de conservación. En esta oportunidad describiremos con detalle el horno 14 y expondremos algunos elementos importantes de los casos restantes.

\section{La excavación y los materiales identificados}

A partir de la evidencia superficial del H14 se definieron dos cuadrículas de excavación: la $\mathrm{C} 1$ de 1,70 × 2 m se trazó alojando en el sector central la estructura metalúrgica. En dirección sur se marcó la $\mathrm{C} 2$ de 2,5 x 2,7 m. Se utilizó un procedimiento de excavación de tipo estratigráfico (Carandini 1997 [1981]). Como resultados se obtuvieron datos que permitieron conocer la estructura completa del horno y la estratigrafía al interior del mismo así como la presencia de sectores externos con desechos metalúrgicos. Respecto de estos últimos, la C2 mostró detritos materiales que permitieron delimitar cuatro unidades estratigráficas (UEA) (Figura 2).

La UEA $n^{\circ} 1$ está conformada por una capa homogénea y muy compacta de sedimento blanco de textura fina y aspecto pulverulento (calcita). Este estrato aparece en el sector centro-norte de la cuadrícula a los $60 \mathrm{~cm}$ desde el nivel de inicio de la excavación y se proyecta progresivamente hacia el sur. Su espesor varió entre 8 y $12 \mathrm{~cm}$.

La UEA $n^{\circ} 2$, ubicada en la esquina noroeste de la $\mathrm{C} 2$, presenta un sedimento arenoso suelto con desechos de concreciones calcáreas y materiales de aspecto tubular. Este depósito aparece a los $62 \mathrm{~cm}$ y llega hasta los $78 \mathrm{~cm}$ de profundidad. Se une con la UEA n ${ }^{\circ} 1$ y n $^{\circ} 3 \mathrm{~A}$.
La UEA nº 3 se distribuye en dos zonas -A y B- localizadas hacia los perfiles oeste y sudeste, respectivamente. Son montículos compuestos de fragmentos de leños carbonizados, unos pocos restos de escorias y desechos no vitrificados sobre una matriz de ceniza. En una publicación anterior habíamos remarcado la presencia de montículos de carbón a una distancia regular desde los hornos (Spina y Giovannetti 2014). En el caso del H14, a 3,3 m hacia el sudoeste, se pudo observar en superficie uno de estos montículos, lo que nos lleva a pensar que los desechos de la zona A son los extremos del mismo, posiblemente producto de limpiezas sucesivas del horno.

Por debajo de la UEA $\mathrm{n}^{\circ} 1$ se identificaron fragmentos terrosos cocidos -posiblemente restos de pared de hornos-dispersos hacia el centro de la cuadrícula con evidencias de quemado en su cara inferior. Una vez removidos, se halló inmediatamente una gruesa capa de carbón y cenizas (UEA n ${ }^{\circ} 4$ ), que se corresponde con la estratigrafía presente al interior del horno y que comentaremos a continuación.

Los únicos hallazgos materiales que no se relacionan específicamente con actividades extractivas en la $\mathrm{C} 2$, son tres fragmentos cerámicos de estilo local (Belén) y el llamativo hallazgo de una pieza textil de tonalidades rojizas, justo en el acceso a la cámara inferior.

\section{Estructura de los hornos}

Al finalizar la excavación de ambas cuadrículas, pudimos obtener una imagen completa del horno 14. Su estructura consta de cuatro componentes: una antecámara inferior, dos cámaras -superior e inferior- y un sector intermedio de tierra cocida perforado por conductos cilíndricos verticales (Figuras 3 y 4 ).

Cámara superior. Este componente presenta en su base un diámetro cercano a los $110 \mathrm{~cm}$. Sus paredes se elevan y se curvan inclinándose hacia el interior y finalizando en una gran abertura horizontal, que podría considerarse tentativamente como una especie de chimenea. En la actualidad las paredes alcanzan una altura de $71 \mathrm{~cm}$ y su espesor se mantiene aproximado a los $10 \mathrm{~cm}$. La cara interna de las mismas presenta un enlucido blanco con sectores termoalterados. Estas zonas quemadas y vitrificadas por el fuego se distribuyen por encima de aquellos conductos que comunican ambas cámaras. La base 

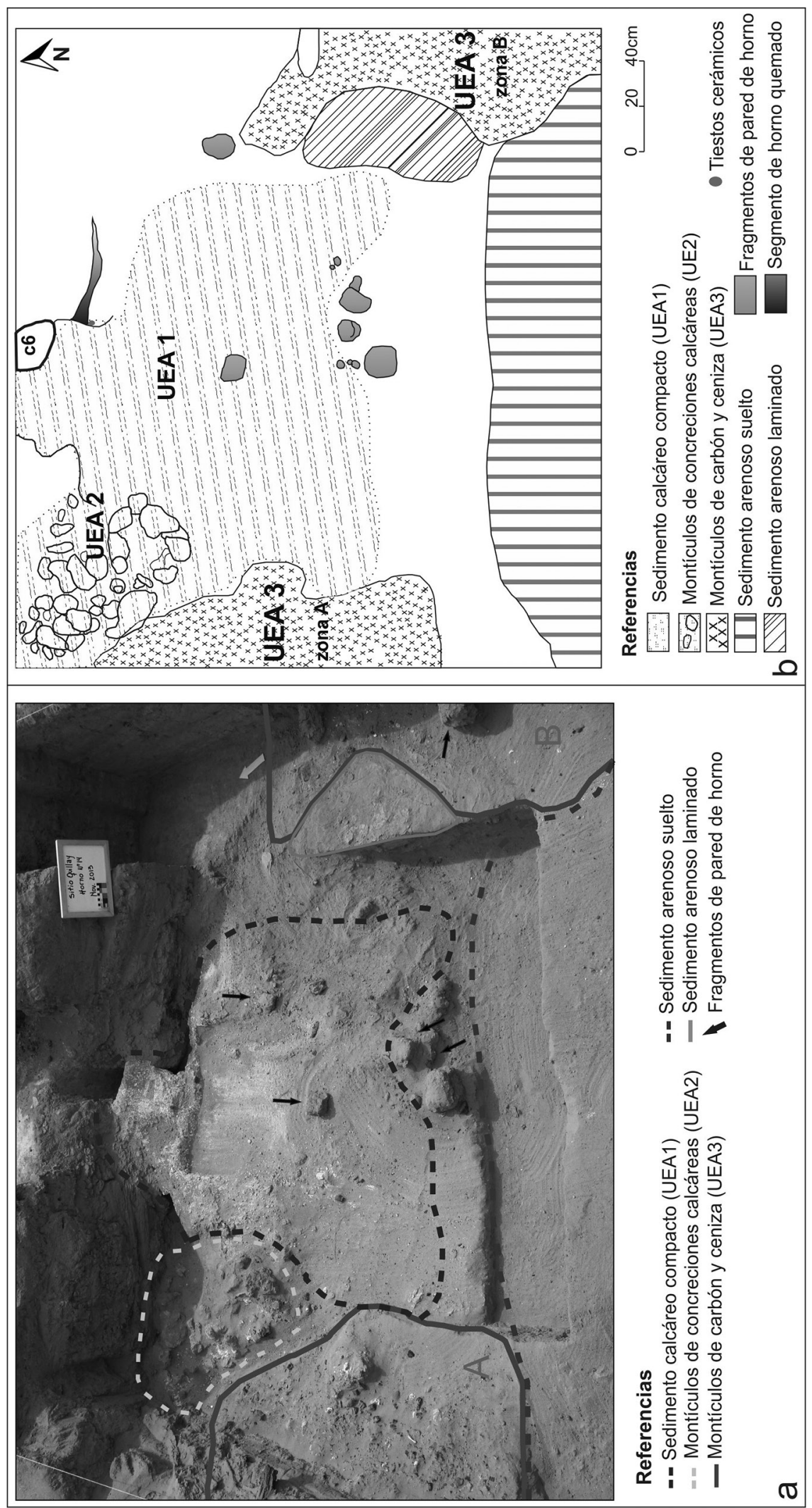

范

这要余

岂. 峞

은 $\frac{\pi}{4}$

诺

드응ㄱ $>$

잉

莡 夏

융 $\frac{8}{0}$

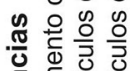

跑

这 क

ऽ : | 


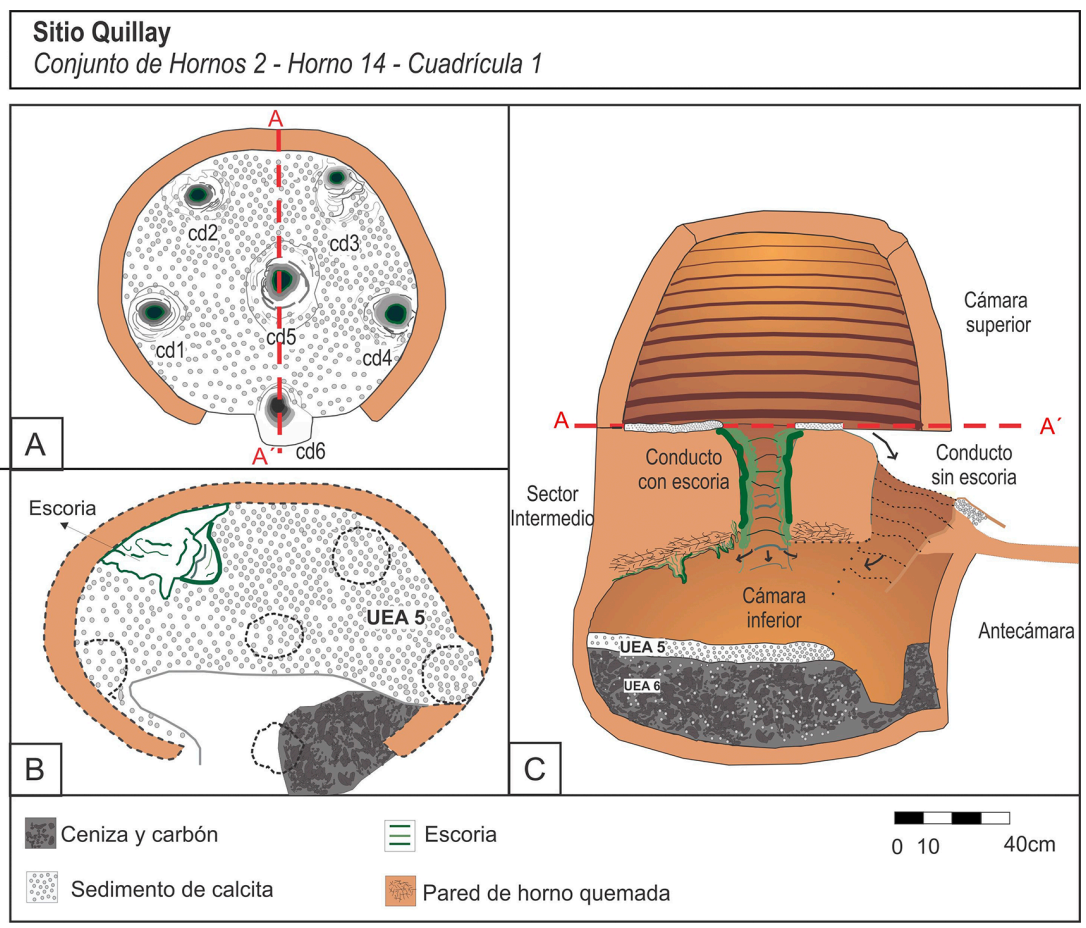

Figura 3. Croquis del Horno 14: A y B - Vista en planta de la cámara superior e inferior, respectivamente; $\mathrm{C}$ - Corte longitudinal de la estructura completa.

Drawing of Furnace 14: A and B-plant view of the upper and lower chamber respectively; $B$ - Longitudinal section of the complete structure.

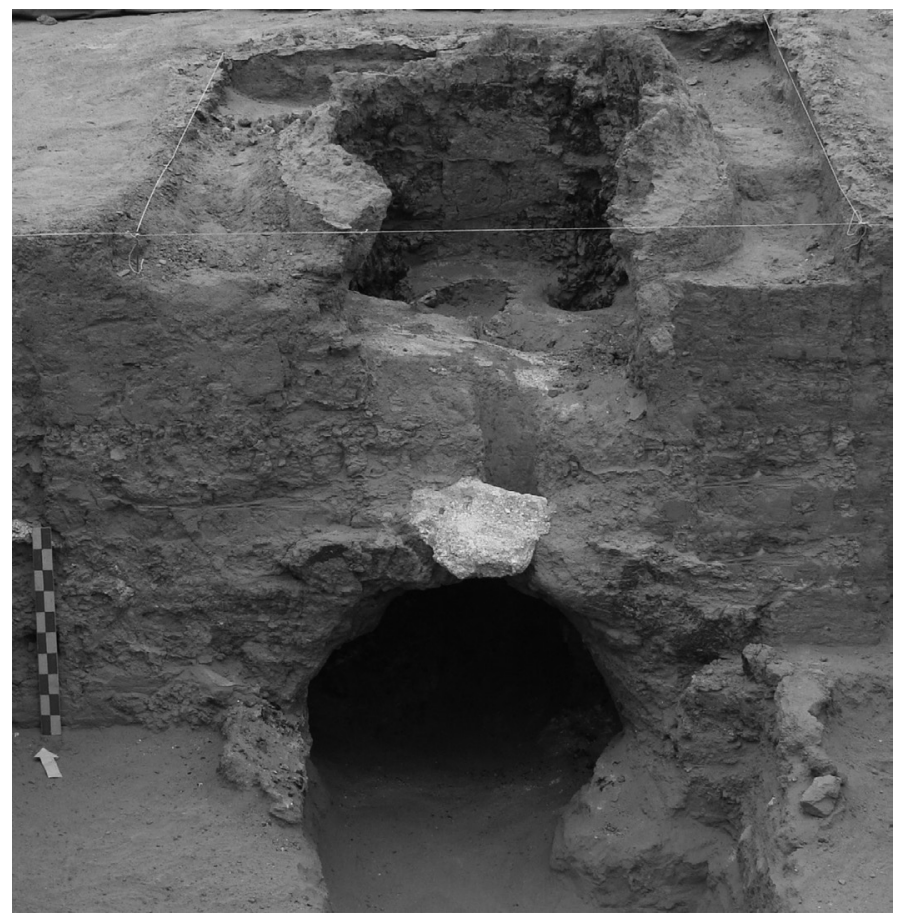

Figura 4. Fotografía del Horno 14 totalmente excavado. Photograph of Furnace 14 fully excavated. 
de esta cámara es una superficie plana, con una capa de sedimento blanco calcáreo que se apoya sobre el sector intermedio.

Sector intermedio. Esta zona, que separa ambas cámaras, posee $40 \mathrm{~cm}$ de espesor, siendo atravesado por seis conductos dispuestos de manera radial: uno central y otros cinco casi equidistantes y adyacentes a la pared del horno (Figura 3A). Poseen en el segmento más superficial -en la base de la cámara superior- diámetros de entre 17 y $30 \mathrm{~cm}$ que van disminuyendo con la profundidad, en parte, por acumulación de escoria solidificada. De los seis conductos, cinco presentan lados recubiertos por escoria negra con tonalidades verdes y rojas. El n ${ }^{\circ} 6$ deja ver su material constitutivo de tierra cocida y no presenta ningún tipo de alteración producto de la fundición.

Cámara inferior. Vista en planta y en corte longitudinal adquiere forma de elipse con un diámetro mayor de $130 \mathrm{~cm}$. Sus paredes presentan una altura máxima de $75-80 \mathrm{~cm}$ y se encuentran alisadas y tiznadas de hollín. El techo de la cámara muestra sectores quemados, zonas fuertemente vitrificadas y escoria en los alrededores de los conductos. Este material vítreo adquiere aspecto de estalactitas que fluyó y solidificó en su camino hacia abajo.

La estratigrafía de esta cámara presentó abundante sedimento arenoso suelto de relleno y posteriormente dos estratos. El superior (UEA n ${ }^{\circ} 5$ ) compuesto por un sedimento blanco y compacto identificado por difracción de rayos x como calcita $\left(\mathrm{CaCO}_{3}\right)^{3}$. Posee un espesor de entre 8 y $10 \mathrm{~cm}$ inclinándose abruptamente hacia el sector izquierdo y hacia el exterior de la cámara. Visto en planta este sedimento se registra hacia la mitad de la cámara inferior, justo por debajo del conducto $\mathrm{n}^{\circ} 5 \mathrm{y}$ desde allí se expande hacia el fondo de la cámara. Sobre este estrato, y por debajo del conducto $\mathrm{n}^{\circ} 2$, se halló una escoria de grandes dimensiones y aspecto fluido (Figura 3B).

Por debajo de esta unidad se identificó una gruesa capa de sedimento suelto, carbones y cenizas con algo de calcita (UEA n ${ }^{\circ} 6$ ), constituyendo una especie de montículo que alcanza un espesor de $35 \mathrm{~cm}$ y entra en contacto con la base de este componente. Los carbones se distribuyen en toda la extensión de la cámara aunque no uniformemente. La acumulación de fragmentos de mayor tamaño se encontró en el sector derecho cercano a la boca de acceso, así como por fuera de la misma. Allí los leños carbonizados alcanzaron $11 \mathrm{~cm}$ de largo y diámetros de hasta $12 \mathrm{~cm}$. Si bien estos materiales están en proceso de análisis, una primera identificación determinó que las muestras pertenecen mayormente al género Prosopis sp., abundante en la zona de estudio. Este dato nos brinda indicios acerca de la selección de combustibles óptimos, ya que el algarrobo es una madera dura de gran poder calorífico, lo cual debió asegurar el fuego para posibilitar las tareas extractivas (González 2004a).

Antecámara inferior. Para describir este sector debemos hacer referencia al horno 7 del conjunto $\mathrm{n}^{\circ} 1$, dado que, si existía antecámara en el horno 14 , se habría destruido por completo. Posiblemente aquellos fragmentos de pared de horno con evidencias de quemado-que fueron referenciados en la descripción de la C2- serían parte de este componente. Un indicio de esto último sería la disposición de estos fragmentos hallados justo por encima de la abertura de la cámara inferior.

El horno 7 se ubica sobre el perfil de una cárcava profunda, lo que contribuye a su destrucción. La estructura mantiene en pie el segmento inferior de la cámara superior y conserva gran parte de la antecámara, cuya excavación permitió completar la forma de los hornos. Este componente también pudo observarse en otros ejemplares que a lo largo del tiempo quedaron expuestos a la superficie (Figura 5).

Vista de frente, la antecámara adquiere un aspecto subrectangular con ángulos redondeados, midiendo $90 \mathrm{~cm}$ de ancho por $62 \mathrm{~cm}$ de alto. El espesor de la pared varía entre 9 y $11 \mathrm{~cm}$. La abertura de la antecámara se ensancha a medida que se introduce en la cámara inferior. Presentó un contexto similar al horno 14 y restos de escoria de aspecto fluido que solidificó, manteniendo su conexión con uno de los conductos insinuados en la cámara superior (Figura 6).

\section{Primeros Avances sobre las Escorias}

Las escorias son los desechos resultantes de actividades pirometalúrgicas, ya sean estas operaciones de reducción de minerales o de refinación de un metal impuro (Miller y Killick 2004). Sus características composicionales y microestructurales nos brindan información respecto de estos procedimientos, los materiales empleados, 


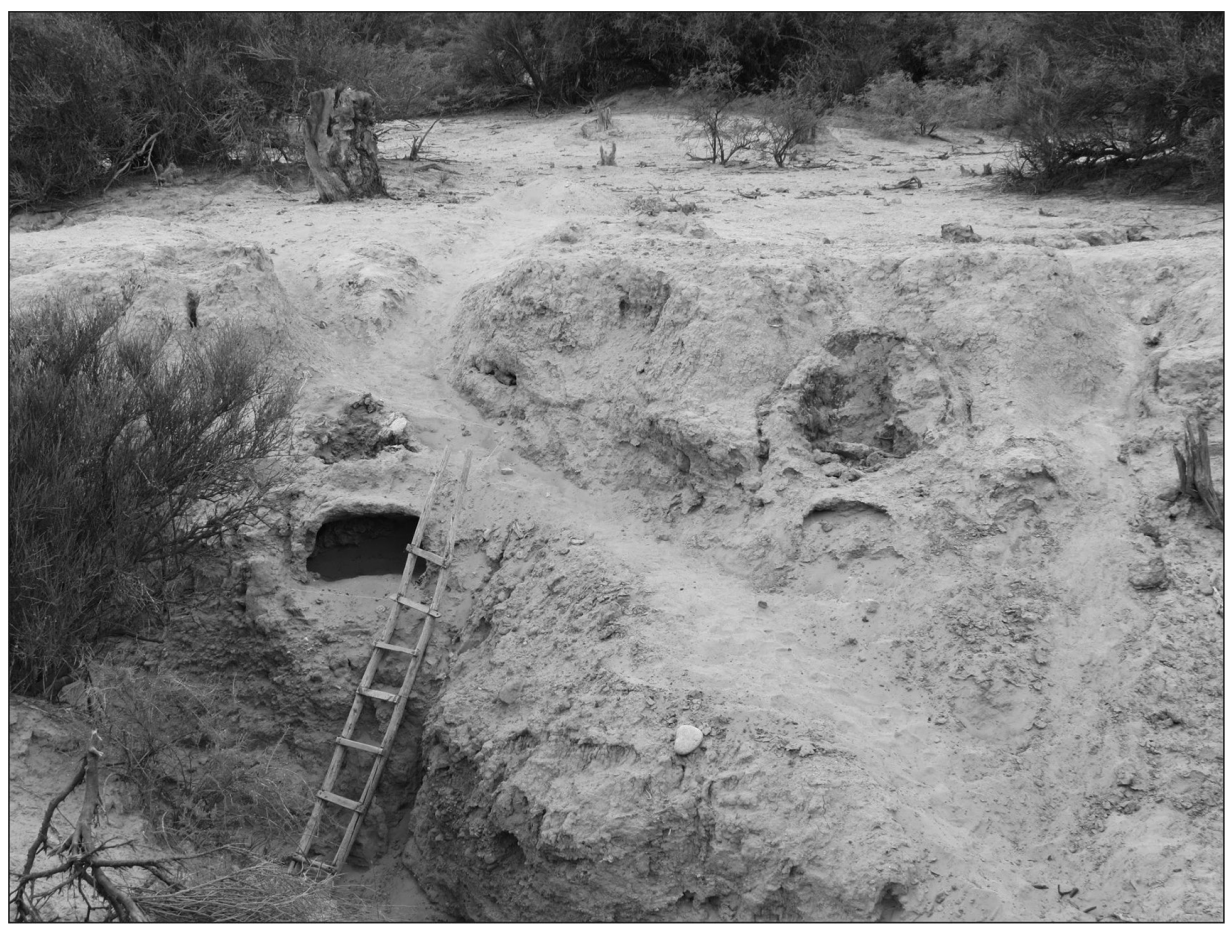

Figura 5. Se observa la cámara superior y la antecámara del horno 7 y 9, expuestos y alterados por la erosión. Showing the upper chamber and the antechamber in furnace 7 and 9, exposed and altered by erosion.

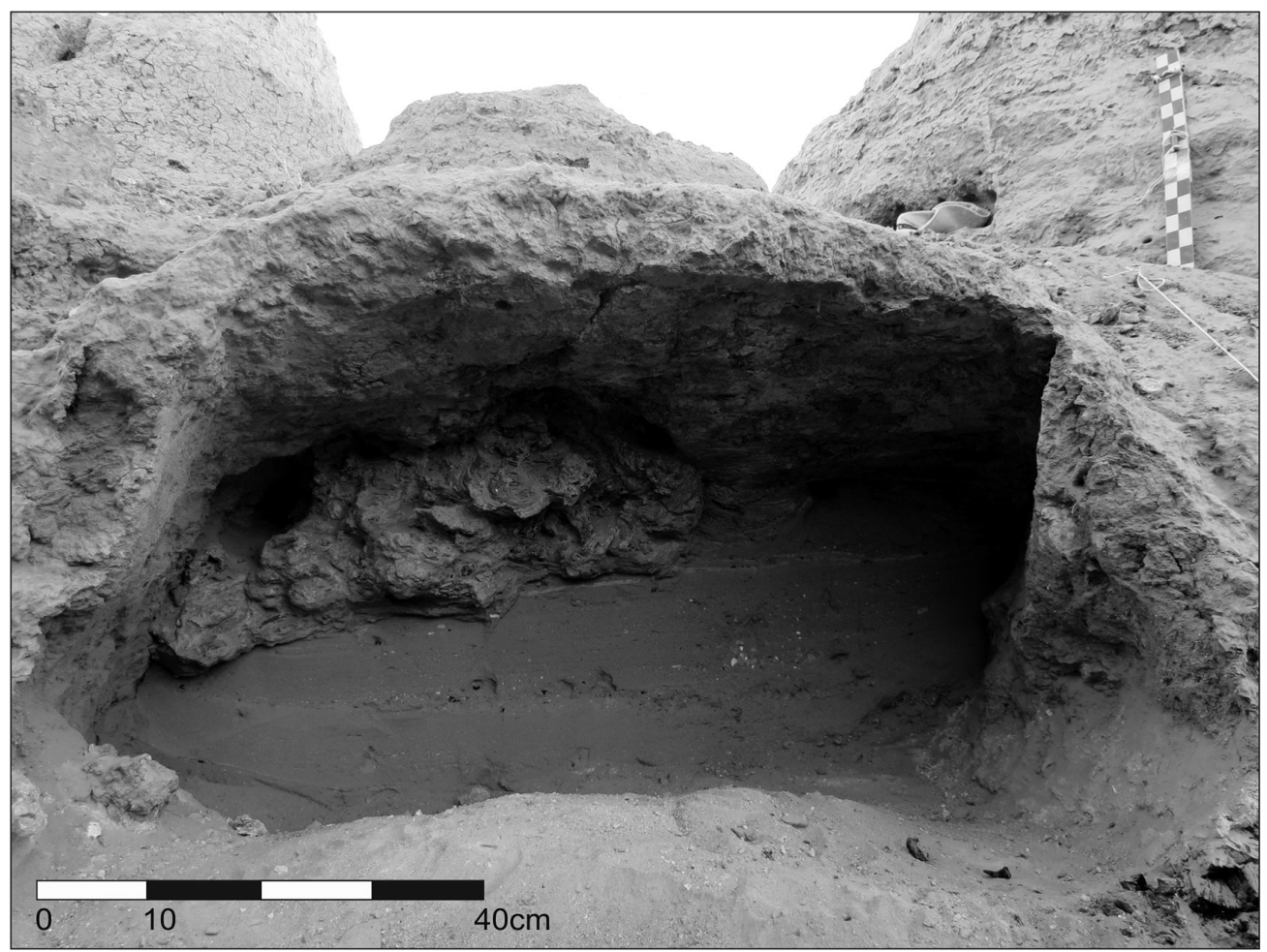

Figura 6. Imagen de la escoria solidificada de aspecto fluido, vista desde la antecámara del horno 7. Image of solidified slag of fluid appearance, seen from the antechamber of furnace 7. 
las condiciones de óxido-reducción y las temperaturas alcanzadas (Bachmann 1982; González 2004a; Hauptmann 2007).

En este apartado mostraremos los resultados obtenidos de análisis químicos realizados en escorias del horno 14. El objetivo fue conocer los materiales procesados y discriminar la operación metalúrgica que les dio origen para dilucidar la función del horno. Las tres muestras analizadas fueron seleccionadas de la cámara inferior (M1), del montículo de desechos de la zona A de la C2 (M2) y del conducto ${ }^{\circ} 3$ del horno (M3). Para su análisis al microscopio electrónico de barrido ambiental $(\text { ESEM })^{4}$ se confeccionaron superficies planas mediante corte con disco abrasivo, desbaste manual y pulido mecánico con alúmina. Luego se observaron a distintos aumentos y se efectuó microanálisis elemental de sus fases por espectroscopia dispersiva de rayos X (EDAX). Además, las M1 y M3 fueron analizadas por difracción de rayos $\mathrm{X}(\mathrm{DRX})^{5}$ para la identificación de compuestos químicos.
La observación de las M1 y M2 permitió detectar inclusiones poliédricas y nodulares de coloración blanca cuyos espectros indicaron la presencia de $\mathrm{Cu}$, $\mathrm{Fe} \mathrm{y} \mathrm{S}$ en algunas fases y $\mathrm{Cu}$ y $\mathrm{Fe}$ en otras, ambas insertas en una matriz vítrea de aluminosilicatos y alcalinos (Figura 7). Como se puede observar en la Figura 8, por DRX estos compuestos fueron identificados como bornita (Cu5FeS4) y delafosita $(\mathrm{CuFeO} 2)$, incluso fueron detectados óxidos de cobre (cuprita) (tanto en M1 y M3). Las escorias contienen además abundante sílice (cuarzo), silicatos del grupo olivino (fayalita), feldespatos (plagioclasas) y óxidos de Fe (magnetita).

La presencia de bornita en las escorias indica el procesamiento primario de menas sulfuradas de cobre (Bachmann 1982). Diversos estudios técnicos han demostrado que en escorias de fundición de minerales de esta clase es frecuente hallar prills sulfurosos (llamados mata) compuestos por $\mathrm{CuFeS}$, $\mathrm{CuS}$ o $\mathrm{FeS}$, que quedan incluidas en la matriz debido a su baja solubilidad en silicatos (Bachmann 1982:

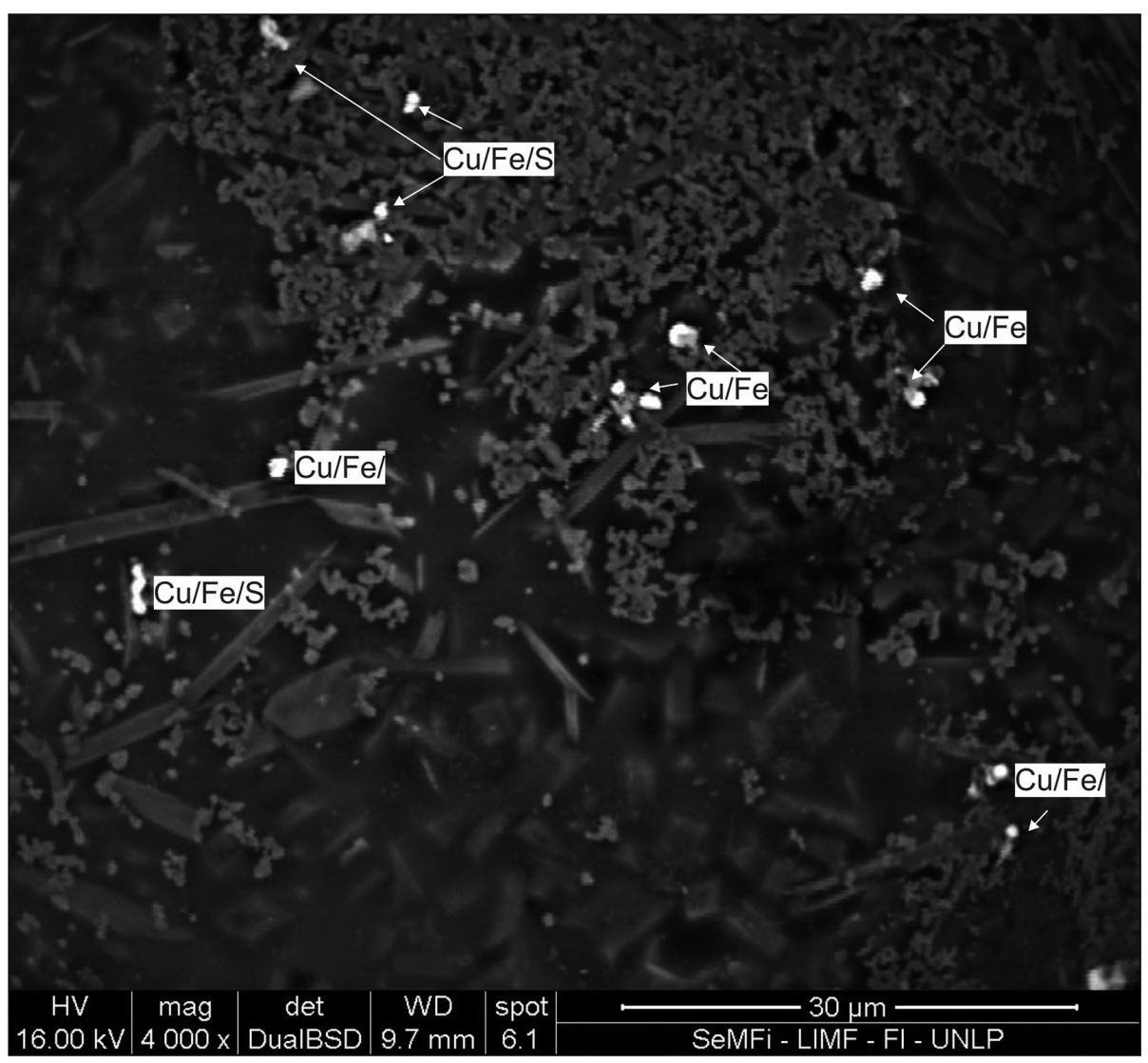

Figura 7. Escoria con glóbulos de CuFeS y CuFe. Imagen ESEM con electrones retrodifundidos de la M1. Slag with CuFeS and CuFe globules. ESEM Image with backscattered electrons of M1. 


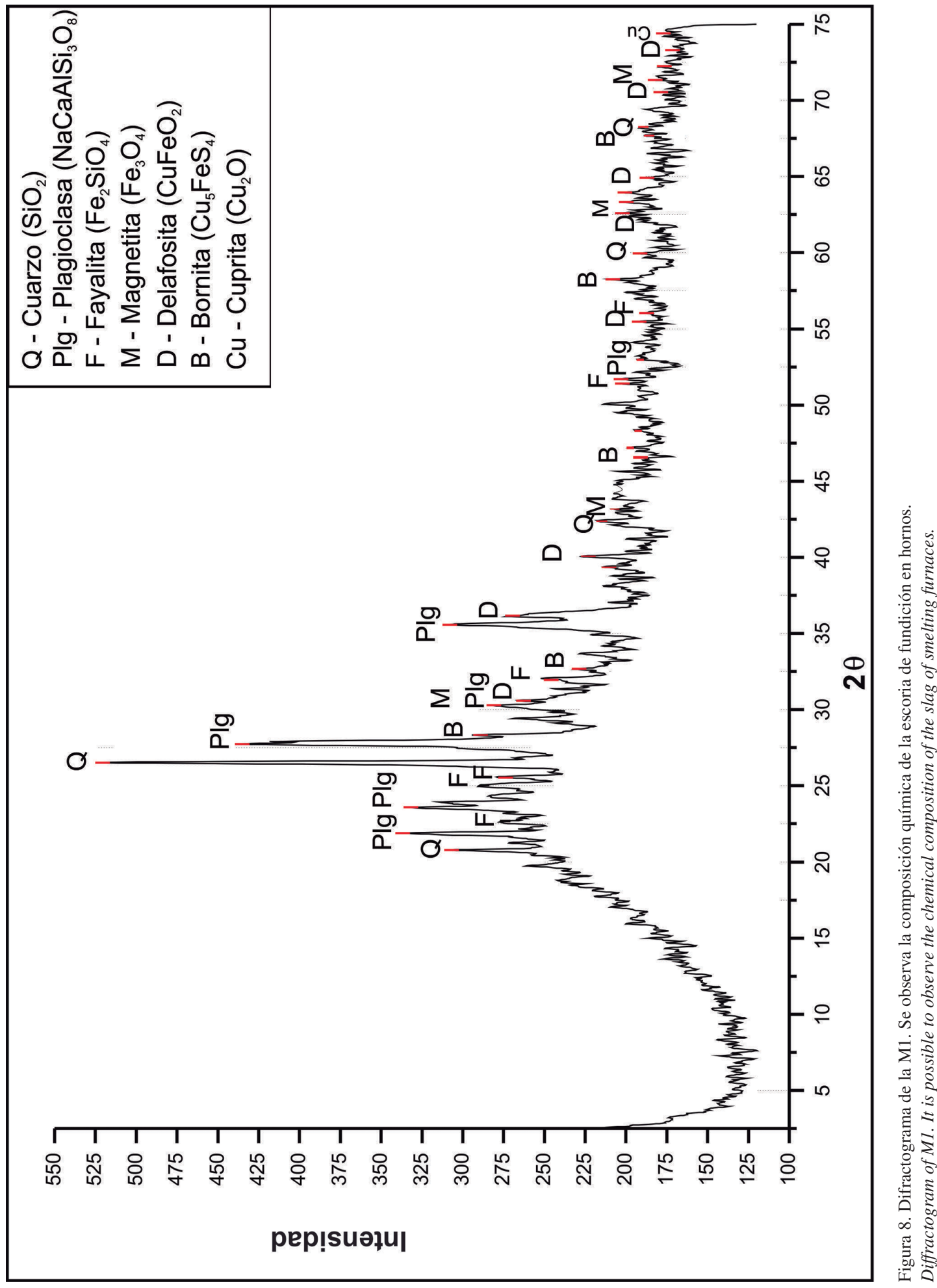


placa IXf, Xd; Mei y Rehen 2005:tabla 4; Merkel y Shimada 1988:6; Zori et al. 2013:figura 8) como parece ser el caso aquí presentado. Estas inclusiones serían precipitados secundarios, producto de una etapa de tostación del sulfuro para su conversión a óxido metálico, acorde con los procesos descritos por Bachmann (1982). Dicho procedimiento requiere un ambiente rico en oxígeno y ante la presencia de hierro, pueden cristalizar óxidos de $\mathrm{Cu}$ y $\mathrm{Fe}$ (como la delafosita) y óxidos de hierro (como la magnetita y hematita) (Hauptmann 2007).

Hay que agregar que en el sector de recintos se han recuperado 16 materiales refractarios hallados en superficie. Son fragmentos de cuencos -crisoles y cucharas-, tapones y un posible molde. Sus características morfológicas, medios de sujeción y la presencia de recubrimientos con una sustancia de hueso molido, responden a elecciones técnicas ampliamente difundidas entre la poblaciones del NOA (González 2004a; Spina y Gluzman 2017). Tres muestras contienen adherencias metálicas que fueron identificadas por EDS como relictos de cobre altamente oxidados. La ausencia de otros elementos metálicos (como Sn o As) sugiere que en estos cuencos se habrían efectuado nuevas instancias de fundición de cobre, antes que tareas de aleación.

En definitiva, los resultados obtenidos hasta el momento permiten sostener que el horno fue utilizado en la metalurgia extractiva del cobre, con instancias de tostación y reducción. La presencia de cobre metálico en los crisoles confirma que las actividades productivas del sitio estuvieron orientadas a la obtención de este metal. Sin embargo, por el momento no se han recuperado evidencias que remitan a actividades del trabajo del metal. En este sentido, es factible que el cobre obtenido haya sido trasladado a otros talleres para la manufactura de objetos conforme a los principios organizativos del Tawantinsuyu.

\section{Algunas Propuestas del Funcionamiento de los Hornos de Fundición}

Queremos presentar un conjunto de alternativas posibles que nos permitirían entrar en el mundo del beneficio del mineral en Quillay, aunque sabemos que los futuros estudios experimentales proveerán información fundamental para contrastar las hipótesis respecto del funcionamiento de los hornos.

A partir de las evidencias observadas proponemos que las dos cámaras de mayor tamaño cumplirían, cada una, un rol diferente en esta primera etapa de fundición. La función de la cámara superior sería la de contener el mineral triturado, antes de comenzar el proceso con aplicación de calor. Para el caso del horno 14 , sobre los conductos -a excepción del n ${ }^{\circ} 6$ fue colocado un cúmulo de mena de cobre y fundente silíceo, posiblemente arena o cuarzo molido. Un análisis de la distribución de la escoria remanente indica que el material fluyó desde la cámara superior a la inferior a través de los conductos. En el interior de estos se observa escoria con aspecto fluido y de estalactitas, encontrándose incluso conductos colapsados y totalmente bloqueados, como en los hornos 7 y 17 .

Algunas preguntas que debemos tener en cuenta para cualquier estructura de fundición son las siguientes: ¿por qué sectores se recuperaría el metal y por cuáles se produciría el vaciado de los desechos? Para Quillay podemos avanzar hasta las siguientes inferencias que analíticamente podemos dividir en dos etapas. La primera, relativa a la preparación de la cámara inferior previo inicio de la fundición; y la segunda, a las actividades pirometalúrgicas propiamente dichas.

La cámara inferior presenta una única abertura frontal de gran tamaño, lo que nos indica que por allí se controlarían actividades como la preparación del combustible y las áreas de drenaje. Con la cámara superior se habría compartido el control de la temperatura, la circulación de gases y la fluidez de los materiales.

A partir de los hallazgos relativos a la disposición espacial en el interior de la cámara inferior, proponemos que se habría diseñado una arquitectura de división del espacio vinculada con distintas acciones. El abundante carbón localizado a la derecha indicaría que este sector estaba destinado a la producción y control de la combustión. Hacia el fondo se registra un montículo artificial coronado por una gruesa capa de material calcáreo que se extiende por la cámara inferior, abarcando la zona que coincide con un sector justo por debajo de los conductos que poseen escoria adherida (Figura 3B). Suponemos que este montículo habría sido construido luego de la limpieza del material residual de fundiciones previas y antes de la colocación de la leña a usar en un nuevo evento. En su construcción se buscó una pendiente hacia el sector izquierdo (mirando desde la abertura hacia el interior) para dirigir el material fundido, que caería por los conductos desde la cámara superior una vez funcionando el horno. 


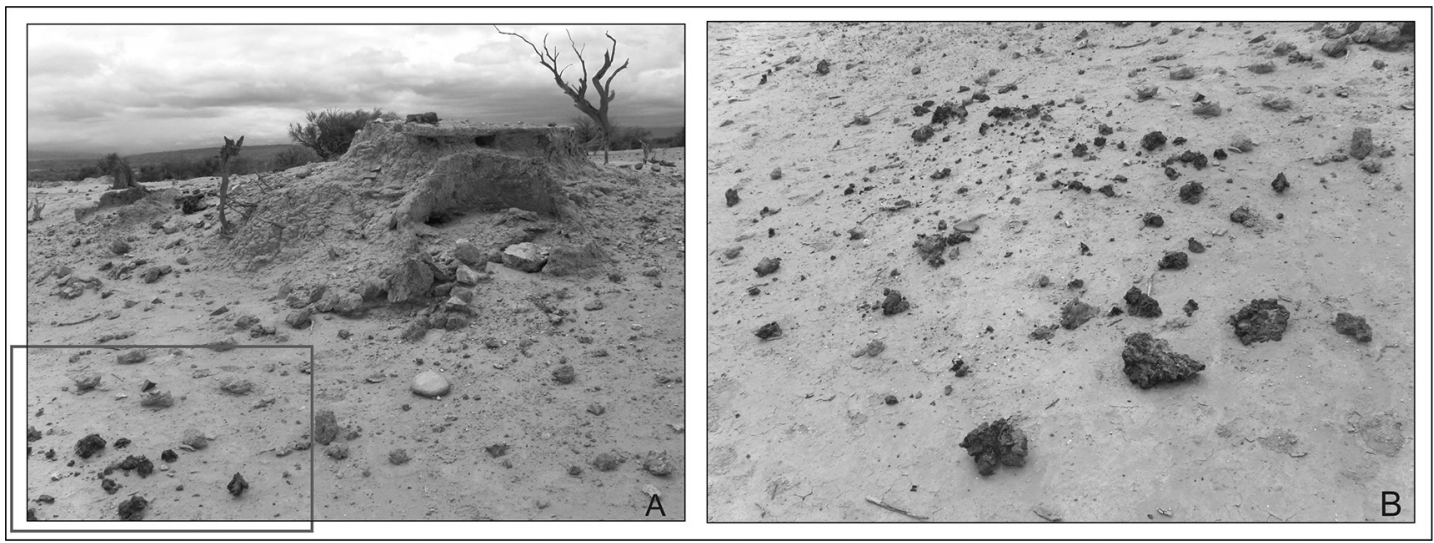

Figura 9. (A) Se observa el horno 14 (izquierda) y el 15 (derecha) junto a fragmentos de pared y escorias halladas en sus alrededores. (B) Ampliación de las escorias de aspecto fluido.

(A) The Furnaces 14 (left) and 15 (right) are seen with wall fragments and slag found in their surroundings. (B) Enlargement of slag of fluid appearance.

La segunda etapa, ya en el momento de la fundición, nos obliga a plantear al menos dos hipótesis de la manera en que habría sido recuperado el cobre obtenido. La primera alternativa plantea un sistema donde la escoria fluiría hacia afuera de la cámara, aprovechando la pendiente generada en el sector izquierdo, que además cuenta con una proyección hacia el exterior a juzgar por la presencia de calcita. El cobre quedaría depositado en una especie de oquedad en el interior de la cámara, siendo recolectado al finalizar el proceso y una vez enfriado. Cabe aclarar que el mismo contendría todavía restos de escoria adherida por lo cual es muy probable que necesitaran de nuevas fundiciones para purificarlo. Las evidencias con las que contamos para avalar esta posibilidad son los numerosos fragmentos de escoria de aspecto fluido (Figura 9) que aparecen por fuera de cada horno, así como también fragmentos de material blanco de morfología tubular -aún no identificado químicamente-, pero que darían cuenta de una alteración por temperatura y de movimiento direccional de la materia.

La segunda posibilidad implicaría que no existiera drenaje hacia afuera y que todo el fluido se dejara enfriar dentro del horno. El metal, de mayor densidad, se concentraría en la parte inferior de una posible cavidad calcárea, mientras que, por arriba, se concentraría la escoria. Una vez enfriado, el material sólido se extraería mecánicamente, fragmentando el producto en la búsqueda del metal. Esta posibilidad cuenta con un dato significativo registrado en la excavación de las cámaras inferiores de los hornos
14 y 7. En ambos casos, por debajo de uno de sus conductos, se halló una gran masa de material fundido, a simple vista reconocido como escoria, con aspecto fluido y solidificado in situ (Figura 6).

\section{Síntesis y Reflexiones Finales}

Los resultados de las excavaciones de los hornos de fundición identificados en Quillay permitieron conocer la morfología completa de estas estructuras y una serie de materiales residuales asociados a los mismos. En primer lugar describimos en detalle los cuatro componentes que conforman su estructura: cámaras superior e inferior, sector intermedio y antecámara inferior. Los análisis de escorias metalúrgicas y las adherencias metálicas en materiales refractarios sugieren el empleo de estas estructuras para la metalurgia extractiva del cobre. El análisis integral de estos datos nos permitió proponer hipótesis acerca del funcionamiento a nivel estructural de los hornos. Como se apuntó previamente, las cámaras cumplirían distintas funciones dentro del proceso de extracción metalúrgica. Por la superior se realizaría el ingreso y deposición de la mena y fundentes. Los conductos que comunican ambas cámaras servirían para el tiraje direccionando el calor en sentido ascendente, y en sentido inverso la caída del material líquido. Además, la cámara inferior habría funcionado como espacio de combustión y también de vaciado del horno. Asimismo, la gran boca de la antecámara, la abertura en la cámara superior y en el caso del 
horno 14 , el conducto sin alteración ( $\left.n^{\circ} 6\right)$, habrían cumplido tareas de ventilación.

Más allá de las interpretaciones respecto de la dinámica de funcionamiento de los hornos, las evidencias encontradas en el horno 14 marcan algunas particularidades que nos permiten discriminar un segundo evento. La presencia y extensión del estrato de calcita (UEA nº2) en la cuadrícula 2 nos estaría indicando un posterior bloqueo en el acceso a la cámara inferior del horno que es posible pensarlo en el marco de una acción ritual de cierre de la actividad metalúrgica. El hallazgo de un fragmento textil en posición horizontal justo en la boca de esta cámara nos orienta en esta dirección. Según los primeros estudios, esta pieza presenta un hilado en $\mathrm{Z}$ característico de tejidos de carácter ritual (Pérez de Micou, comunicación personal 2016). Refuerza esta hipótesis el conocimiento de ofrendas realizadas en contextos de actividades mineras y metalúrgicas, que provienen de estudios arqueológicos y etnográficos (Absi 2005; González 2004b, Van Buren y Mills 2005). Prácticas que adquieren sentido en el marco de la cosmovisión andina, debido a la significativa sacralidad otorgada a los espacios, actividades y valor simbólico de los metales (Cruz et al. 2013; González 1992; González 2004a, 2004b; Lechtman 1978, 1993; entre otros).

Finalmente, al referirnos a los hornos metalúrgicos, vemos que no abundan los registros de estructuras completas para la región Andina ${ }^{6}$, especialmente para el $\mathrm{NOA}^{7}$. En este marco, los recientes estudios en el sitio Quillay aportan información importante de la morfología de los hornos que posibilita indagar en las prácticas de extracción metalúrgica y brinda un nuevo panorama que amplía la diversidad de estructuras de fundición utilizadas durante el Tawantinsuyu. Estamos ante la presencia de contextos productivos de gran magnitud y sistemas tecnológicos originales que no tienen hasta el momento precedente en Argentina. La singularidad de Quillay nos conduce a pensarlo como un centro especializado destinado a la extracción de metal de cobre en el valle de Hualfín que funcionó durante los períodos Tardío/Inka. Los estudios que estamos realizando brindan un escenario donde la articulación de este espacio productivo con el Tawantinsuyu no habría excluido a las poblaciones locales circundantes. Es más, diversas evidencias sugieren que quienes estaban fundiendo en los hornos eran grupos del valle (Spina et al. 2016). Los grupos locales detentaban los saberes necesarios para las prácticas metalúrgicas, manifestados no solo en la destreza expresada en los objetos de bronce registrados en el valle (González 1992), sino también en los contextos domésticos locales de producción metalúrgica identificados en el sitio Campo de Carrizal (Zagorodny et al. 2014).

Agradecimientos: los estudios han sido realizados gracias a una beca doctoral otorgada a la primera autora por la Universidad Nacional de La Plata y al proyecto PIP 0202 de CONICET. Quisiéramos agradecer a la Dra. Marconetto por el reconocimiento preliminar de leños, al equipo del LIMF y a la Dra. Castiñeira por sus colaboraciones en los análisis técnicos y al Dr. González por la lectura del manuscrito. También a todos aquellos que dedicaron su tiempo y esfuerzos en las campañas: César, Gregoria, Gustavo, Lucía y Camila; y quienes nos recibieron con gran afecto en el sitio arqueológico: doña Griselda, Hugo, Rita, Marcela y sus hijos. Finalmente, agradecemos a los evaluadores por sus comentarios y sugerencias que contribuyeron a la mejora del manuscrito.

\section{Referencias Citadas}

Absi, P. 2005. Los Ministros del Diablo. El Trabajo y sus Representaciones en las Minas de Potosí. PIEB, IRD, IFEA, La Paz.

Angiorama, C. y F. Becerra 2010. Antiguas evidencias de minería y metalurgia en Pozuelos, Santo Domingo y Coyahuayma (puna de Jujuy, Argentina). Boletín del Museo Chileno de Arte Precolombino 15:81-104.

Bachmann, H.G. 1982. The Identification of Slags from Archaeological Sites. London Institute of Archaeology, Vol. 28. Occasional Publication $\mathrm{N}^{\circ} 6$.

Balesta, B., N. Zagorodny y F. Wynveldt 2011. La configuración del paisaje Belén (Valle de Hualfín, Catamarca). Relaciones de la Sociedad Argentina de Antropología XXXVI: 149-175.

Barba, A.A. 1817 [1640]. Arte de los Metales. Tribunal de Minería de Lima, Lima.

Bargalló, M. 1967. La "guayra", horno de fundición del antiguo Perú. Estudio de las referencias de los cronistas. Minería 79:43-49.

Boman, E. 1991 [1908]. Antigüedades de la Región Andina de la República Argentina y del Desierto de Atacama. Universidad Nacional de Jujuy, San Salvador de Jujuy.

Capoche, L. 1959 [1585]. Relación General de la Villa Imperial de Potosí, 1585. Ed. De Lewis Hanke, Tomo CXXII. Biblioteca de autores españoles, Madrid. 
Carandini, A. 1997 [1991]. Historias en la Tierra. Manual de Excavación Arqueológica. Traducción de Xavier Dupré Raventos. Crítica, Barcelona.

Cieza de León, P. 1922 [1553]. La Crónica del Perú. Calpe, Madrid.

Cruz, P., E. Crubézy y P. Gérard 2013. Los adoratorios de altura Inkaicos. Una mirada desde el Cerro Cuzco, Departamento de Potosí, Bolivia. Memoria Americana 21:93-120.

De Nigris, M.R. y O.P. Riart 2011. El uso de los hornos de pachamanca y guayra para la fundición en los Andes. De Re Metallica 16:21-31.

González, A.R. 1959. Breve noticia de las investigaciones arqueológicas efectuadas en el valle de Hualfín, campaña 1952. Revista del Museo de Ciencias Naturales y Tradicional de Mar del Plata 1(1):79-86.

González, A.R. 1980. Patrones de asentamiento incaico en una provincia marginal del imperio. Implicancias socioculturales. Relaciones de la Sociedad Argentina de Antropología. Tomo XIV, $\mathrm{N}^{\circ} 1: 63-82$.

González, A.R. 1992. Las Placas Metálicas de los Andes del sur. Contribución al Estudio de las Religiones Precolombinas. KAVA, Berlín.

González, L.R. 2004a. Bronces sin Nombre. La Metalurgia Prehispánica en el Noroeste Argentino. Ed. Fundación Ceppa, Buenos Aires.

González, L.R. 2004b. El arte del cobre en los Andes prehispánicos: Historias de poder, brillos y colores. El Arte del Cobre en el Mundo Andino 8-59.

González, L.R. 2010. Fuegos Sagrados. El taller metalúrgico del sitio 15 de Rincón Chico (Catamarca, Argentina). Boletín del Museo Chileno de Arte Precolombino 15:47-62.

González, A.R. y G.L. Cowgill 1975. Cronología arqueológica del valle de Hualfín, Pcia. De Catamarca, Argentina: obtenida mediante el uso de computadoras. Actas Primer Congreso de Arqueología Argentina pp. 383-395. Rosario.

Hauptmann, A. 2007. The Archaeometallurgy of Copper: Evidence from Faynan, Jordan. Springer, Berlin.

Lechtman, H. 1978. Temas de metalurgia andina. En Tecnologías Andinas, compilado por R. Ravines, pp. 489-520. Instituto de Estudios Peruanos, Instituto de Investigación Tecnológica Industrial y de Normas Técnicas, Lima.

Lechtman, H. 1993. Technologies of power: The Andean case. En Configurations of Power in Complex Societies, editado por J. Henderson y P. Netherly, pp. 243-280. Cornell University Press, Ithaca.

Lechtman, H., P. Cruz, A. Macfarlane y S. Carter 2010. Procesamiento de metales durante el horizonte medio en el altiplano surandino (Escaramayu, Pulacayo, Potosí, Bolivia). Boletín del Museo Chileno de Arte Precolombino 15:9-27.

Lynch, J. 2013. Construcción y organización del espacio incaico al norte del Valle de Hualfín, Catamarca, Argentina. BAR International Series 2506, England.

Miller, D. y D. Killick 2004. The identification at Southern African archaeological sites. Journal of African Archaeology 2:23-47.

Mei, J. y T. Rehen 2005. Copper smelting from Xinjiang, NW China. Part I: Kangcun village, Kuche county, c18th century AD. Historical Metallurgy 39:96-105.
Petersen, G.G. 1970. Minería y metalurgia en el Antiguo Perú. Arqueológicas 12:1-152.

Raffino, R.A. 2009. Poblaciones Indígenas en Argentina. Urbanismo y Proceso Social Precolombino. Emecé Editores S.A., Buenos Aires.

Raffino, R.A., R.J. Alvis, L.N. Baldini, D.E. Olivera y M.G. Raviña 1983-1985. Hualfín - El Shincal - Watungasta. Tres casos de urbanización Inka en el N.O. argentino. Cuadernos del Instituto Nacional de Antropología 10:425-458.

Raffino, R.A., D.J. Gobbo, A. Iácona y R.A. Moralejo 2013. La minería y metalurgia de los Inkas del Kollasuyu. Actas del $\mathrm{V}$ Congreso Nacional de Arqueología Histórica, Tomo 1, pp. 187216. Editorial Académica Española. Buenos Aires.

Raffino, R.A., R. Iturriza, A. Iácona, A. Capparelli, D. Gobbo, V. Montes y Y.R. Vázquez 1996. Quillay: centro metalúrgico Inka en el Noroeste Argentino. Tawantinsuyu 2:59-69.

Rivera Casanovas, C. 2008. Aproximación inicial a la explotación minera y metalurgia prehispánica en la región de San Lucas, Chuquisaca. En Mina y Metalurgia en los Andes del Sur, desde la Época Prehispánica hasta el siglo XVII, editado por P. Cruz y J.J. Vacher, pp. 139-200. Institut français d'études andines e Institut de la recherche pour le développement, Sucre.

Rodríguez Orrego, L. 1979. La Encrucijada: survey of site of metallurgical activity in Northwest Argentina. En Pre-Columbian Metallurgy in South America, editado por E. Benson, pp. 203207. Dumbarton Oaks, Washington, DC.

Salazar, D., B. Mille, V. Figueroa, F. Balestro, C. Perlés, C. Perles, J. Berenguer, D. Bourgarit, P. Corrales, L. Carroza y A. Burens 2013. Metalurgia indígena en el distrito Miño-Collahuasi, Norte de Chile (Siglos X a XVII): Tecnología y organización de la producción de cobre. Ponencia presentada en el XVIII Congreso Nacional de Arqueología Argentina, La Rioja.

Shimada, I., S.M. Epstein y A.K. Craig 1982. Batán Grande: A prehistoric metallurgical center in Peru. Science 216:952-959.

Spina, J., K. Liotta, M. Valderrama, E. Ferraris y M. Giovannetti 2016. La cocina de Quillay. Restos alimenticios recuperados en la excavación del recinto 1 . Ponencia presentada en el XIX Congreso Nacional de Arqueología Argentina, Tucumán.

Spina, J. y M. Giovannetti 2014. Metalurgia prehispánica en el valle de Hualfín. Nuevos datos sobre Quillay. Revista Intersecciones en Antropología 15:473-477.

Spina, J. y G. Gluzmán 2017. Hacia una comprensión de las cerámicas metalúrgicas. Caracterización morfológica y funcional de moldes y crisoles de dos sitios del Noroeste Argentino. En Investigaciones Arqueométricas: Técnicas y Procesos, editado por A, Rocchietti, F. Ribero y D. Reinoso, pp. 91-104. Editorial Aspha, Buenos Aires.

Téreygeol, F. y P. Cruz 2014. Metal del viento. Aproximación experimental para la comprensión del funcionamiento de las wayras andinas. Estudios Atacameños. Arqueología y Antropología Surandinas 48:39-54.

Van Buren, M. y B.H. Mills 2005. Huayrachinas and tocochimbos: Traditional smelting technology of the southern Andes. Latin American Antiquity 16:3-25.

Vetter Parodi, L., S. Petrick Casagrande, Y. Huaypar Vasquez y M. Mac Kay Fulle 2008. Los hornos metalúrgicos del sitio Inca 
de Curamba (Perú): estudio por DRX, espectroscopia Mossbauer y datación por métodos de luminiscencia. Bulletin de l'Institut Français d'Études Andines 37:451-475.

Williams, V. 1995. Arqueología Incaica en la Región CentroOeste de Catamarca (República Argentina). Tesis para optar el grado de Doctor en Ciencias Naturales, Facultad de Ciencias Naturales, Universidad Nacional de La Plata, La Plata.
Zagorodny, N., C. Angiorama, F. Becerra, M.J. Pérez Pieroni 2015. Evidencias de actividades metalúrgicas en el sitio Campo de Carrizal (Belén, Catamarca). Intersecciones en Antropología $16: 439-450$

Zori, C., P. Tropper y D. Scott 2013. Copper production in late prehispanic northern Chile. Journal of Archaeological Science 40:1165-1175.

\section{Notas}

1 Los trabajos citados recapitulan los relatos coloniales respecto de wayras andinas. Allí se pueden encontrar mayores detalles de las variantes morfológicas de estos hornos.

2 Se encuentra en desarrollo la tesis doctoral de la Lic. Spina ("Arqueometalurgia Inka en el Noroeste argentino. Estudio del sitio Quillay y abordaje tecno-estilístico de piezas de colección" FCNyM, UNLP) siendo los datos publicados aquí parte de la misma.

3 Datos obtenidos del análisis por DRX por método en polvo llevados a cabo en el Servicio de Rayos X del Museo de La Plata, UNLP. Para la identificación de compuestos químicos se emplearon los programas PC-Identify y X'pert Highscore 2.0, complementados con lectura manual.

4 Se empleó un microscopio modelo FEI ESEM Quanta 200 equipado con un espectrómetro de rayos $\mathrm{X}$ dispersivo en energías (EDS) modelo EDAX SDD Apollo 40. Equipo disponible en el servicio de microscopia del Laboratorio de Investigaciones en Metalúrgica Física (LIMF), Facultad de Ingeniería, UNLP.

5 Ver nota 3

6 Ver por ejemplo los casos de los sitios de Batán Grande (Shimada et al. 1982) y Curamba en Perú (Vetter Parodi et al. 2008), Pulacayo (Lechtman et al. 2010) y Pututaca (Rivera Casanovas 2008) en Bolivia, Miño y Ujina en Chile (Salazar et al. 2013).

7 Existen varias referencias de hornos metalúrgicos prehispánicos en el NOA (Angiorama y Becerra 2010; Boman 1991 [1908]; González 2010; Rodríguez Orrego 1979; entre otros), pero son muy pocos los que se hallaron completos y en buen estado de conservación como aquel ejemplar de Potrero Chaquiago (Williams 1995) y los aquí presentados. 